\title{
Severe Intestinal Bleeding in a Woman with Glanzmann Thrombasthenia
}

\author{
Raquel Mesquita, Inês Santos, Helena Monteiro \\ Serviço de Medicina 2.1, Hospital dos Capuchos, Centro Hospitalar de Lisboa Central, Lisbon, Portugal
}

How to cite this article: Mesquita R, Santos I, Monteiro H. Severe intestinal bleeding in a woman with Glanzmann thrombasthenia. EJCRIM 2017;4: doi:10.12890/2017_000796.

Conflicts of Interests: The Authors declare that there are no competing interests.

Acknowledgements: The Authors would like to thank Dr Jaime Ramos for making the images available.

This article is licensed under a Commons Attribution Non-Commercial 4.0 License

\section{ABSTRACT}

Glanzmann thrombasthenia (GT) is a rare inherited disorder associated with abnormal platelet function. Non-surgical bleeding is common and can be life-threatening. A 70-year-old woman with GT presented with a 3 week history of melena and asthenia. She had hemoglobin of $3.8 \mathrm{~g} / \mathrm{dL}$. Both upper and lower endoscopies were inconclusive. Video capsule endoscopy showed multiple angioectasias and erosions in the distal ileum. Following several days of recurring intestinal hemorrhage, only treatment with recombinant activated factor VII proved to be effective, enabling patient stabilization with no further bleeding. Control and prevention of bleeding among these patients is imperative and remains challenging.

\section{LEARNING POINTS}

- Glanzmann thrombasthenia is a rare inherited bleeding disorder of platelet function caused by a quantitative or qualitative defect of the platelet membrane glycoprotein (GP) IIb/IIla (integrin allbß3) complex.

- Bleeding is a concern in patients with GT due to its potential risk of severity and uncontrollability. It also greatly impacts on the quality of life of the patient.

- Recombinant FVIla has been reported to be a safe and effective hemostatic agent when bleeding is not responsive to local management, antifibrinolytics or platelet transfusion.

\section{KEYWORDS}

Glanzmann thrombasthenia, bleeding, rFVIIa

\section{CASE DESCRIPTION}

We present the case of a 70-year-old woman, daughter of first-degree cousins, with a known diagnosis of Glanzmann thrombasthenia (GT). The patient also had asthma, right obstructive uropathy with stent placement, and a history of hemorrhoids. She was on bronchodilation therapy and enteral iron supplementation. She experienced several hospitalizations since childhood associated with bleeding, particularly from the urinary and gynecological tracts, requiring multiple red blood cell and platelet transfusions.

In the emergency department, the patient complained of melena and asthenia over the previous 3 weeks. She had no history of abdominal pain, vomiting or syncope. During the physical examination, she was conscious, pallid, and blood pressure was 78/49 mmHg. Anal examination revealed melena, while abdominal examination was unremarkable. The patient was admitted for stabilization and further investigation. 
Methods and Procedures

Results of laboratory tests showed hemoglobin of $3.8 \mathrm{~g} / \mathrm{dL}$ with normal platelet count. She underwent volume resuscitation and was given a perfusion of pantoprazole and aminocaproic acid, and red blood cell and platelet therapy. Emergency upper endoscopy showed small erosions of the esophagus and stomach probably related to nasogastric tube insertion. The first set of blood analysis indicated transferrin saturation of $6 \%$, with normal folic acid and cyanocobalamin values. During the first 3 days, the patient presented with recurring low intestinal hemorrhage associated with persistent anemia and transient hemodynamic instability.

Because the patient's condition was refractory to the continued transfusional and antifibrinolytic therapy support, it was decided to start recombinant activated factor VII therapy (NovoSeven ${ }^{\circledR}$ ) $90 \mu \mathrm{g} / \mathrm{kg} 6 / 6 \mathrm{~h}$. CT angiography revealed high-density material in the ascendant and transverse colonic lumen, potentially a sign of subacute hemorrhage, while a late colonoscopy showed only multiple friable polyps, without stigma of recent hemorrhage. Given the continued bleeding of unknown origin, video capsule endoscopy was immediately performed.

This indicated multiple and visible angioectasias and erosions along the entire distal ileum, which rendered a surgical procedure unfeasible (Fig. 1). A decision was made to continue treatment with NovoSeven ${ }^{\circledR}$ complemented by regular intravenous iron supplementation. This therapy was followed for 16 days without complication. The patient improved gradually and neither further melena occurred nor new transfusions were required. At the time of discharge (day 30), the patient was asymptomatic with hemoglobin of $9.8 \mathrm{~g} / \mathrm{dL}$.

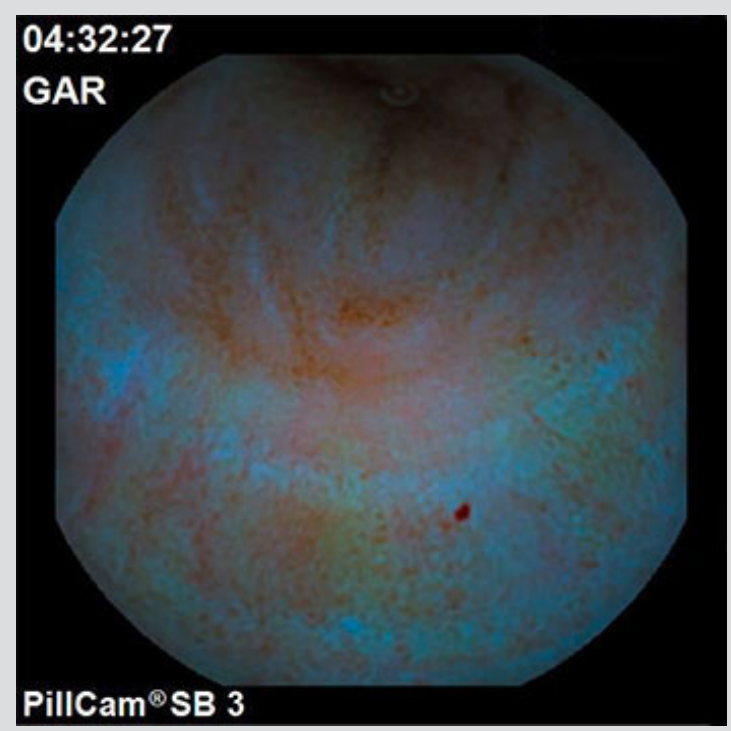

Figure 1. Video capsule endoscopy image showing multiple and visible angioectasias and erosions along the entire distal ileum

\section{DISCUSSION}

Glanzmann thrombasthenia is a rare autosomal recessive bleeding disorder with an incidence of approximately 1:1 million. In areas where marriage between close family relatives is common, the incidence can be as high as $1: 200,000^{[1]}$. It is characterized by a normal platelet count and morphology but an abnormal platelet function, due to a qualitative or quantitative genetic platelet surface receptor disorder of

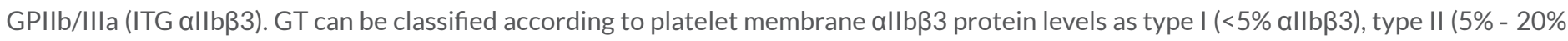

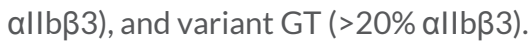

Patients develop signs of bleeding first in childhood, typically spontaneous mucocutaneous bleeding as easy bruising and purpura (43\%), epistaxis (80\%) and gingival bleeding (62\%) ${ }^{[2]}$. Bleeding from genital, urinary and gastrointestinal tracts is less common but potentially more severe and unpredictable. Bleeding complications are frequent following trauma or surgical procedures, including dental extraction, as well as during child birth. Bleeding symptoms are confined to GT patients with homozygous or compound heterozygous for GPIIb/IIla mutations. To date, there is no established relationship between the platelet membrane allbß3 protein levels and the severity of bleeding.

Some patients develop an acquired form of GT usually resulting from an autoantibody attack on platelet $\alpha$ llb $\beta 3$. This condition is frequently associated with autoantibody disorders such as non-Hodgkin lymphoma or immune thrombocytopenic purpura.

Managing bleeding episodes is often difficult and serious bleeding may be fatal. Notwithstanding this, the overall mortality rate is low. Standard treatment for GT consists of platelet transfusion when local measures and fibrinolytic drugs fail to control the bleeding. 
However, this therapy is associated with the risk of developing alloimmunization to GPIlb/Illa or human lymphocyte antigen, potentially resulting in platelet refractoriness. In recent years, the use of recombinant factor VIla (rFVIla) has increased significantly. Data available from a large patient registry, an international survey, and multiple case reports support the effectiveness and safety of using rFVIla in the treatment of bleeding episodes as well as in the prevention of bleeding during invasive, surgical or dental procedures among GT patients ${ }^{[1,3]}$. It has been suggested that doses of $90 \mathrm{mcg} / \mathrm{kg}$ and higher have significantly increased the activation of factor IX and X, thereby increasing thrombin generation and promoting platelet aggregation ${ }^{[4]}$.

This particular patient was treated with a similar dosage of rFVIla and the duration of the therapy adjusted to the clinical condition, leading to a successful recovery. Effectively, there are no established guidelines concerning the treatment of GT. This may be due to the fact that monitoring the hemostatic response of platelet transfusions in patients with GT is particularly challenging - either through clinical improvements in bleeding or through functionally platelet laboratory testing ${ }^{[5]}$. Additionally, the rarity of this condition hinders clinical trials. rFVIla has been frequently used off label for bleeding and surgical procedures, irrespective of platelet antibodies or refractoriness.

Stem cell transplantation as a curative treatment is possible in only a few selected patients with poor quality of life, suffering from persistent severe bleeding and refractory to hemostatic treatment regimens. Research on genetic therapy has been gaining significant attention in the past decade, showing promising results as a curative option.

In conclusion, GT is a rare condition, and this case reinforces the established idea that, in such cases, recurring intestinal hemorrhage may be a serious complication which is difficult to manage, particularly if the surgical option is unfeasible. Control and prevention of bleeding among patients with GT is imperative. Physicians should at all times be able to recognize signs of platelet refractoriness and know how to select the best treatment regimen for each condition. This process may be optimized in two phases: firstly, the definition of adequate response to platelet transfusion and, secondly, the determination of the optimal rFVIla treatment regimen according to the severity of the bleed.

\section{REFERENCES}

1. Poon MC, d'Oiron R, Zotz RB, Bindslev N, Di Minno MN, Di Minno G, et al. The international, prospective Glanzmann Thrombasthenia Registry: treatment and outcomes in surgical intervention. Haematologica 2015;100:1038-44.

2. Di Minno G, Zotz RB, d'Oiron R, Bindslev N, Di Minno MN, Poon MC. The international, prospective Glanzmann Thrombasthenia Registry: treatment modalities and outcomes in non-surgical bleeding episodes in patients with Glanzmann thrombasthenia. Haematologica 2015;100:1031-37.

3. Rajpurkar M, Chitlur M, Recht M, Cooper DL. Use of recombinant activated factor VII in patients with Glanzmann's thrombasthenia: a review of the literature. Haemophilia 2014;20:464-71.

4. Solh T, Botsford A, Solh M. Glanzmann's thrombasthenia: pathogenesis, diagnosis, and current and emerging treatment options. J Blood Med 2015;6:219-27.

5. Chitlur M, Rajpurkar M, Recht M, et al. Recognition and management of platelet-refractory bleeding in patients with Glanzmann's thrombasthenia and other severe platelet function disorders. Int J Gen Med 2017;10:95-99. 